\title{
CAPTURING REFLEXIVITY MODES IN IS: A CRITICAL REALIST APPROACH
}

\author{
François-Xavier de Vaujany \\ CERAG (UMR CNRS 5820) \\ Grenoble university (IAE) \\ 150 rue de la Chimie \\ 38040 Grenoble
}

devaujany@iae-grenoble.fr

\begin{abstract}
:
Critical realism is a subject of growing interest in the IS literature. This article aims at implementing a critical realist framework: Margaret Archer's (2003) internal conversation theory. As a contemporary sociologist, Archer suggests both a general vision of social practice and a typology of reflexivity modes. Her multilayered framework could be extremely useful in overcoming a current limitation in IS: the weakness of reflexivity modelling. Indeed, though much research sheds light on the structureaction relationship, it does not illuminate users' biographical realms and reflexivities. In consequence, some genuine motives in ICT-related practices remain poorly understood. To address this deficiency, this article applies Archer's framework to an IS environment through a meta-analysis of interviews. Results partially confirm the relevance of internal conversation theory and its potential added value to the study of ICT-mediated interactions. A further reflexivity mode and possible re-organizations of the Archer framework are also proposed.
\end{abstract}

\section{Keywords:}

Critical realism; reflexivity; internal conversation; biographical realm; ICT user

This is a draft version of the paper that subsequently appeared with some modification in print. Please cite as: de Vaujany FX. (2008).Capturing reflexivity modes in IS: a critical realist approach. Information and Organization, 18/1, pp. 51-72 


\section{CAPTURING REFLEXIVITY MODES IN IS: A CRITICAL REALIST APPROACH}

\section{INTRODUCTION}

An increasing number of researchers are arguing that critical realism could be a promising perspective by which to reconsider the underpinning philosophy of IS (Dobson, 2001; Mingers, 2004; Smith, 2006; Morton, 2006). According to Smith, the ontology of critical realism could allow for a re-conception of scientific activity as "implicitly predicated upon natural and social realism as well as the concepts of structures and generative mechanisms" (2006; p 193). In parallel to the epistemological stance, IS researchers are increasingly interested in social critical realism and intermediary critical realist frameworks. Bhaskar's transformative models of social action (1979) and Archer's morphogenetic approach (1995) or internal conversation theory (2003) are the subject of growing interest within IS (Mutch, 2002; Smith, 2006). Nonetheless, the bulk of this literature remains extremely theoretical. Compared to a meta-theoretical approach such as structuration theory (see Giddens, 1984), very little research has tried to adapt or apply Bhaskar's or Archer's notions to concrete organizational settings or practices (Morton, 2006).

This article aims to describe and discuss an interesting critical realist lens - internal conversation theory - and to show how it may be helpful in integrating a missing variable in most IS sociological frameworks: sociotechnical reflexivity, i.e. reflexivity related both to social actors and technical artifacts.

Reflexivity is a polysemous word (Johnson and Duberley, 2003). It can be defined as "the concept used in the social sciences to explore and deal with the relationship between the researcher and the object of research" (Brannick and Coghlan, 2006, p 143). In concordance with Giddens' structuration theory, in everyday practice it can also be used to label "the reflexive monitoring of action in situations of co-presence" (Giddens, 1984, p 191). At the individual level ${ }^{1}$, Giddens suggests various degrees of reflexivity, ranging from a casual, everyday reflexivity to a more intense one, where reflexivity itself is at stake. He also underlines some general features of reflexivity (such as its relationship with "ontological security", or the difference between practical and discursive consciousness). However, Giddens does not develop modes of reflexivity, nor any way to apply the concept for study in the field.

Some critical realists have also been interested in the notion, for example Archer with her internal conversation theory. Mutch $(2003,2007)$ has insisted on the potential of this theoretical framework to make sense of reflexivity processes in social modeling. Indeed, research on reflexivity is a crucial agenda for IS, as studies of ICT-related practices may be seen as following a potentially misleading tendency. Influenced by new sociological or psychosociological frameworks, most structurational approaches in IS have largely lost sight

\footnotetext{
${ }^{1}$ Giddens (1991) also deals with "institutional reflexivity".
} 
of the actor-user evolution in favor of more global social dynamics based on "roles", "positions" or "structural properties", that is to say "sociological realms" in contrast to "biographical realms" (Thompson, 2004). As stated by Goffman (1967, 1974), however, the role may not be inhabited by an actor who endorses it merely on this superficial level. Nonetheless, the bulk of structurational works (in counterpoint to Giddens' genuine view, see Walsham, 2001 or Thompson, 2004) are centered on the action-structure integration or interplay (see for instance Desanctis and Poole, 1994 or Orlikowski, 1992, 2000). Giddens' model, his vision of the duality of structure, is the main sensitizing device implemented by IS researchers. In contrast, his visions of reflexivity, of the self, or the influence of modernity at the individual level, are relatively neglected (Barrett and Walsham, 1999; Thompson, 2004).

Likewise, most Actor-Network Theory (ANT) oriented research (applying Callon and Latour, 1990, 1992 or Latour, 1987, 1995) dissolves individuals into a broad 'actant' category (Mutch, 2002), which emphasizes the role of human and non-human actors in networks. But as Fuller (1993, p 342, quoted by Mutch, 2002) points out, this equating of humans to non-humans is "diminishing the value of being a person", and ANT simply puts aside personal reflexivity modes. Our argument could probably be extended to many other theoretical frameworks or applications of theoretical frameworks (see Orlikowski, 2006) such as Lamb and Kling's (2003) theory of social actors, Alter's innovation sociology (2000), DiMaggio and Powell's neo-institutionalism (1991), or Crozier and Friedberg's strategic analysis (1977). Concepts such as 'roles', 'actants', 'systems', 'institutions' or 'actors' are the main target of sociotechnical modelling. This has dramatic consequences. Neglecting the "biographical realm" and actors' individual reflexivities results in a fuzzy vision of some key drivers of sociotechnical change (Thompson, 2004). Indeed, individual users' incentives and motives in ICT-related practices are more or less obscured. But as Walsham (2001, p 73) remarks in the interviews of several ICT users: "What is immediately striking about these stories is the radically different conceptualizations of the nature of their job, their own identity, including their work identity, and the role and perceived value of IT systems in their work life". Some researchers, such as Walsham (2001), Barrett, Sahay and Walsham (2001) or Thompson (2004), do take into account individual levels and the person behind the agent as Giddens does.

This paper will follow a path different from structuration theory, that of internal conversation theory. The reasons for this choice are two-fold. First, Archer has already addressed this from an instrumentation perspective, in Archer (2003). Contrary to Giddens (1979, 1984, 1991), Archer implemented her theoretical framework and thus suggested a methodological approach to operationalize it. Her rationale for this approach is congruent with a core argument put forth in this paper: reflexivity modes are not universal. As suggested by Barrett, Sahay and Walsham (2001, p18), one limitation in Giddens's modeling is "the somewhat homogeneous form of his theory in suggesting the nature of social transformations in current times." Actually, both Archer and Giddens put forward a multilayered view of social transformations, which lead some to emphasize the numerous proximities between structuration theory and the morphogenetic model (see Stones, 2001). Nonetheless, Archer (2003) clearly emphasizes the heterogeneity of reflexivity modes, and her helpful distinction between 'persons', 'agents' and 'actors' is an explicit way to bridge the "biographical" and "social realms" (we will come back to this later). While both structurational and critical realist lenses may illuminate how sociological-biographical realms interact in the study of ICT-related practices, however, they differ on some subtle points concerning technological conceptualization and sociotechnical reflexivity. 
In order to make sense of actors' reflexivity in IS and to relate it to social transformations, a meta-analysis of 120 semi-structured interviews carried out from 1997 to 2004 has been carried out. The interviews were conducted for a study of sociotechnical structuration (from Archer's morphogenetic approach) related to the implementation of intranets and groupware systems. Thus, originally they were not focused on reflexivity modes. Nonetheless, the data collected (interviews, internal and external documents, observations of managers using the technology) turned out to be relevant to the application of internal conversation theory as extrapolated from Archer's morphogenetic model. The data helped us in grasping reflexivity modes and relating them to broader sociotechnical dynamics.

This discussion will begin with a presentation of Archer's social critical realism. An explanation of the development of our initial sociological model (specifically, a critical realist model) will be given before applying this new approach to the reflexivity process. The typology of internal conversations as developed by Archer will also be detailed. The following section aims at applying the internal conversational framework to an IS environment. From a Piagetian perspective, we will strive to assimilate or accommodate Archer's conceptual scheme to sociotechnical internal conversations. Finally, the potential added value and limitations of the paper (both from a theoretical and a methodological standpoint) will be discussed.

\section{ARCHER'S SOCIAL CRITICAL REALISM}

Social critical realism draws mainly on Bhaskar's (1979) and Archer's (1982, 1988, 1995) theoretical frameworks. After presenting Archer's morphogenetic model (the starting point of her critical realist approach), her recent internal conversation theory and typology of reflexivity modes will be explored.

\subsection{Deeper Into Social Change: From the Morphogenetic Approach to Internal Conversations}

Ever more academic articles and special issues on critical realism are being published. A recent issue of Information and Organization was entirely devoted to the framework (see Mingers, 2004; Monod, 2004; Klein, 2004). Several issues of Organization have also published articles dealing with critical realism (see for instance Mutch, 2002 and Fleetwood, 2005), which seems to appeal to a wide audience in managerial and IS research. More broadly, the penetration of critical realism in social research is still modest but real, as shown in figure 1. 


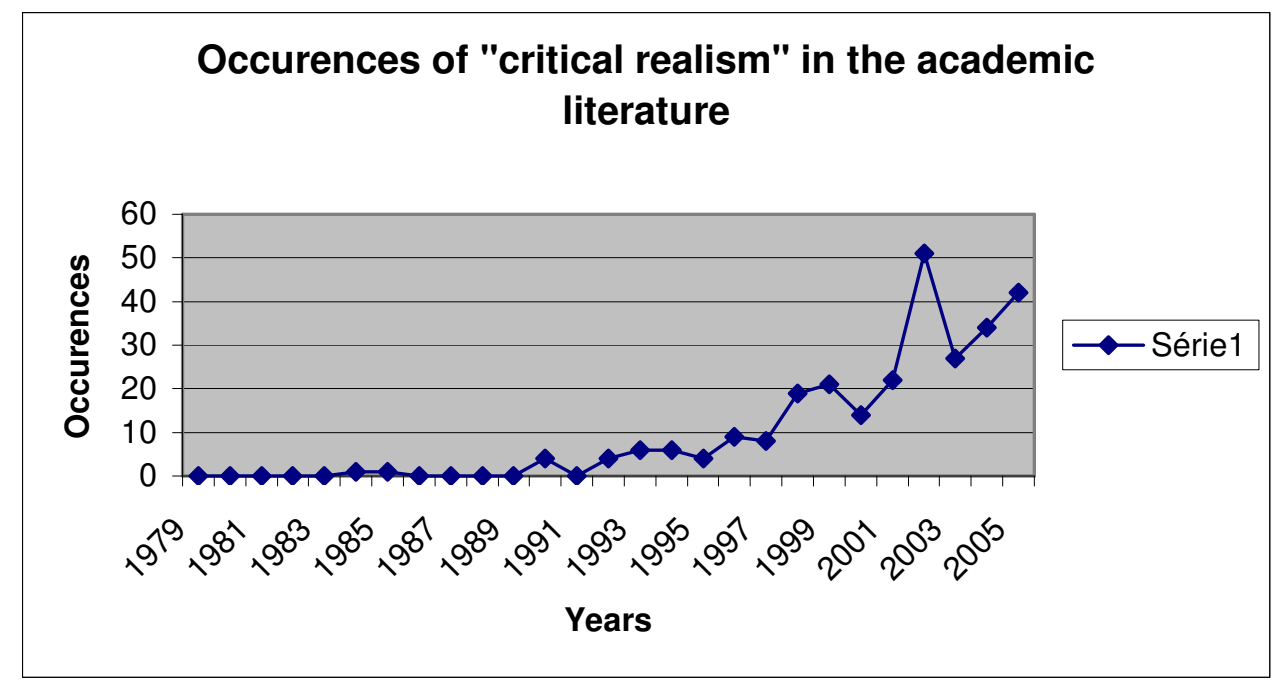

\section{- Figure 1: The penetration of critical realism in social sciences from 1979 to 2006 (analysis due to the author) ${ }^{2}$.}

Among the various disciplines increasingly interested in critical realism, economics (44\% of the total number of occurrences) and management (28\%, of which $6.1 \%$ for information systems) represent the bulk of the users. And this trend keeps growing. Nonetheless, as noted in the introduction, most papers are theory-oriented, i.e. without any empirical data. Less than $5 \%$ of the papers published on critical realism (at least in the database exploited) include fieldwork, either qualitative or quantitative.

But what is critical realism? Positioned as a mediating epistemological stance between interpretativism and positivism (Mingers, 2004), critical realism should thus be an interesting way to overcome some strong dichotomies in IS (see Archer et al, 1998 or Smith, 2006 for a general presentation of critical realist philosophy). In accordance with critical realist philosophy, social critical realism corresponds to the set of intermediary frameworks devoted to social phenomena. Among those, Archer's internal conversation theory is a component of the morphogenetic model she puts forth in her 1988 and 1995 books. In these works, she proposed a critical realist model of social transformations, drawing mainly on Bhaskar's (1979) Transformational Model of Social Action (TMSA). The framework consisted primarily of a representation of a social process in three parts:

(1) An explanation of the conditioning context, which aims at shedding light on the power of structures ${ }^{3}$ that constrain or enable agency;

(2) A description of the agency that will be initiated by various categories of agents whose projects activate specific constraints and enablements (Indeed, "Social structures and

\footnotetext{
${ }^{2}$ Number of academic articles referencing "critical realism" in the body of the text. This work was based on articles indexed on EBSCO (from January to December of each year).

${ }^{3}$ According to Bhaskar, social structures can only be defined relationally as a "position-practice system". He thus elaborates: (1979, p 51): " It is clear that the mediating system we need is that of the positions (places, functions, rules, duties, rights...) occupied (filled, assumed, enacted, etc.) by individuals, and of the practices (activities, etc.), they engage. I shall call this mediating system the position-practice system. Now such positions and practices, if they are to be individuated at all, can only be done so relationally".
} 
cultural systems exercise their causal powers by structuring the situation of action through constraints and enablements, but to the extent that the activation of those causal powers depends on the existential projects that the actors forge in foro interno (no projects: no constraints or enablements), actors can be said to actively mediate their own social and cultural conditioning." Vandenberghe, 2005, p 231);

(3) A revealing of the action's final result, which may reproduce or transform the initial context of conditioning.

Thus, in order to understand morphogenesis at a macro-social level, Archer suggests applying this grid of analysis to illuminate the dual role of structures. Likewise, in Giddens's writings, structures have both enabling and constraining properties. But in contrast to structuration theory, Archer $(1982,1988,1995)$ underlines intransitive properties and a relative exteriority of structures. As regards agency, she also proposes that two kinds of actions and actors can constitute a social system: "primary agents" and "corporate agents". The former have no real group-awareness and no collective project. They are more a sum of individuals than an independent "actor". Generally, they have very few resources at their disposal. In contrast, the latter are a group per se. They have a common goal and share specific resources.

On more micro-social and individual levels, Archer's 1995 model allowed for few means by which to understand how structures constrain or enable agency. Only a "conditioning" process was suggested. This is the mechanism by which structures play a role in actors' reflexivity processes. Structures would determine a social cost (material or psychological) and would give a premium to certain actions. Actors could then conform to the conditioned action, diverge and accept the cost, or even display an inventive capacity and circumvent the constraints posed by structures (Archer, 1995). However, the shortcomings of this reflexivity process in light of a critical realist view are emphasized by Hodgson (2004). He believes that critical realism does not integrate "instincts" and "habits of thought".

Recently, Archer herself has acknowledged the aforementioned weakness of the morphogenetic model (see Archer, 2000, 2003). It is thus in her most recent writings that she began to work out an explicit and dense individual layer in the morphogenetic model. On the basis of the works of Peirce, James and Mead (see Archer, 2003; pp. 53-91) ${ }^{4}$, she suggested drawing on the notion of "internal conversation" to grasp actors' reflexivity processes. Internal conversation can be defined as a continuous mental deliberation in and for action, which is at the heart of the reflexivity process. At the end of the section where she introduces the concept, Archer defines in a relatively clear way its specificities:

"This section has been devoted to how we can be both subject and object to ourselves. It has been maintained that we can do this through our internal conversation by formulating our thought and then inspecting and responding to these utterances, as subject to object. This process is itself the process of reflexivity; it is how we do all these things like monitoring, self-evaluation and self-commitment. (...) Internal dialogue is the practice

\footnotetext{
${ }^{4}$ She introduces these three authors as if they were linked to specific periods in the emergence of the internal conversation concept: "(...) in James, the tentative departure; in Peirce it's incomplete but basically sound development; and in Mead, the deflection which meant its potential remains unrealized. It is because the potential still remains to be reclaimed for modelling our mental lives on the interior dialogue that this excursion is worthwhile" (Archer, 2003; p 57). See also Vandenberghe (2005, p 232).
} 
through which we 'make up our minds' by questioning ourselves, clarifying our beliefs and inclinations, diagnosing our situations, deliberating about our concerns and defining our own project" (2003, p 103).

Finally, she proposes that an internal conversation can be parsed into a tripartite analytical process (see figure 2). First, the conditioning "Me" phase and the emerging results of previous deliberations (also fed through previous interactions) all work to condition actions (T1). Then, the "I" phase evokes an internal conversation (T2 to T3), which defines a future direction that will enrich a kind of exteriorized and projected ego, which will ultimately lead to the "You" phase (T4). In accordance with Archer's 2003 writings, the internal conversation is a sort of missing link between the conditioning context and the agency (see the "I" instance), both being articulated in a recursive way by this reflexive capacity.

Interestingly, this view of reflexivity is consistent with Emirbayer and Mische's (1998) conceptualizations of human agency and temporal orientation. They state that three elements enable actors to shape responses to their environment. First, the "iterational" element is "oriented to past practice in which actors attempt to situate their thoughts about actions in term of familiar routines" (Boudreau and Robey, 1998; p 13). Then, the "projective" element "looks to the future, imagining possibilities for reconfiguring patterns of thought and actions" (ibid). Lastly, the "practical-evaluative" element is present-embedded. It is "the capacity for practical and normative judgments made in the present context of emerging demands, dilemmas and ambiguities" (ibid). Emirbayer and Mische (1998) also suggest a way in which all three elements can be combined. Basically, actors would be more or less influenced by one element at some points, and others later. But "at each moment, however, actors are faced with the contingencies of the past, future and present, making specific actions more difficult to anticipate" (ibid). Thus, the "iterational" element of agency is tightly linked to the "me" modality of internal conversation, i.e. the image of myself worked out through past actions and their effects (such as routines). The "practical evaluative" element would relate more to the "I" modality and to its judgmental and interpretive powers. In contrast, the "projective" element would be more bound with the "you" modality of internal conversations, a vision of the world as a scope of possibilities. 


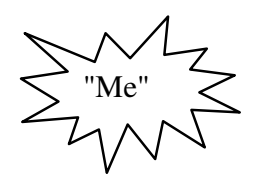

T1 Structural conditioning

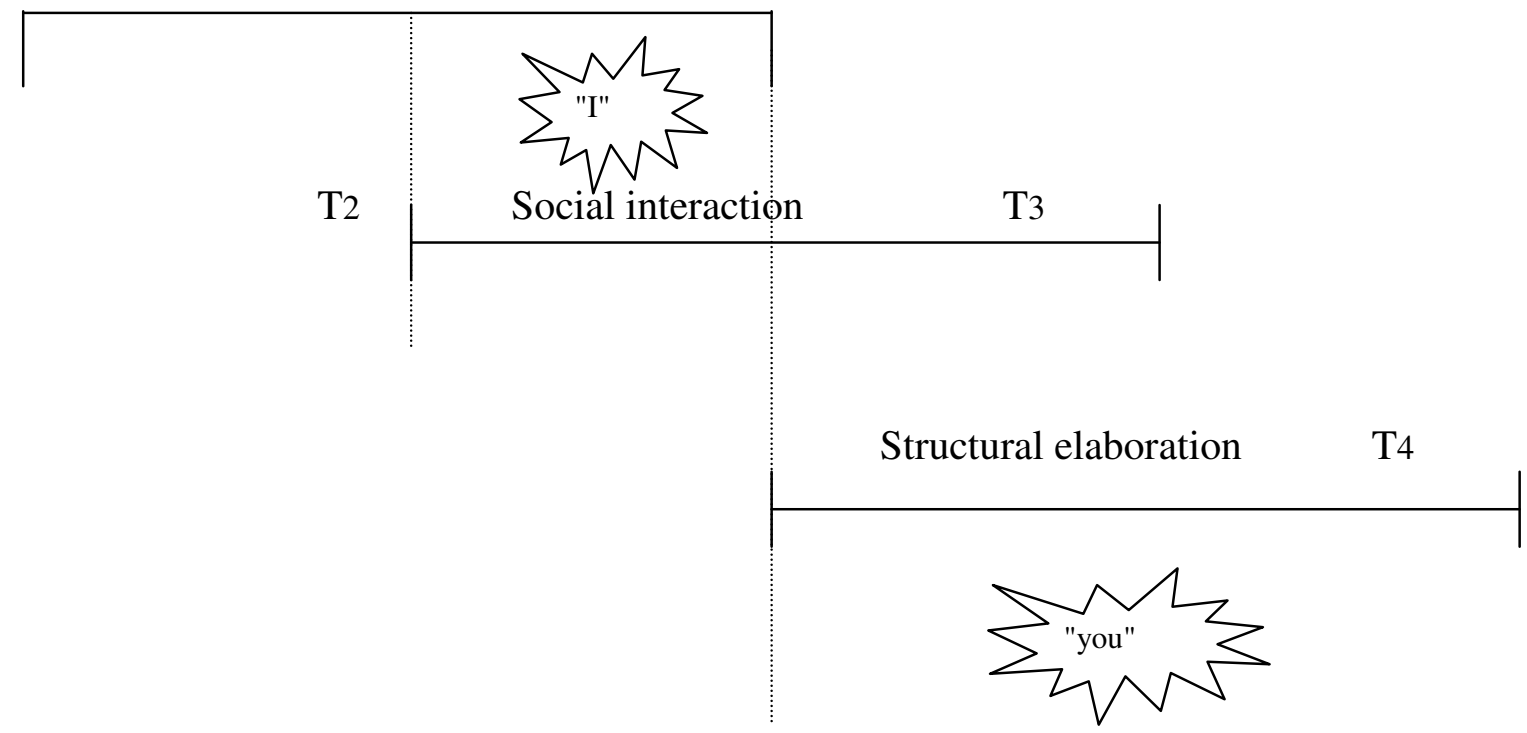

\section{- Figure 2: Reflexivity in social morphogenesis}

In line with this vision, Archer (2003) also offers a stratified conceptualization of individuals as 'persons' (with a personal and body-embedded history) and at the same time both 'agents' (with cultural, economic and demographic features) and 'actors' (related to a social group with specific interests and strategies). The first layer is bound within the "biographical realm", the two others, within the "sociological realm". Besides, Archer also insists on the embodied and emergent nature of the person and self. Thus, "countering Rom Harré's constructivist account of the discursive self, Archer argues with Jean Piaget and Maurice Merleau-Ponty that, even before the acquisition of language and independently of it, the 'differentiation' of the self from the world occurs through the embodied engagement with the world. Once a continuous sense of the self is acquired in early childhood, the formation of personal identity sets in as a life-long quest for authenticity" (Vandenberghe, 2005; p 235).

\subsection{A Typology of Reflexivity Modes}

In order to illustrate empirically her concept of internal conversations, Archer carried out 20 long semi-structured interviews with actors from very heterogeneous social backgrounds. After having presented the aforementioned notion of internal conversation to each interviewee, he/she was asked questions about his/her mental activities (planning, rehearsing, mulling-over, deciding, re-living, prioritizing, imaging, clarifying, imaginary conversations and budgeting), his/her current concerns (what matters most to him/her, such as others, work, self-development, etc.) and his/her life-projects. Finally, three modes of internal conversations emerged, along with two misaligned situations. 
The first mode of internal conversation is communicative reflexivity. It consists of an open internal conversation carried out in a thought and talk manner. An actor displaying this sort of reflexivity thinks while speaking to a precise circle of people with whom he/she shares strong ties. The person has little confidence in his/her own deliberations and prefers relying on others repeatedly to feed his/her reflexivity process. This kind of internal conversation serves to mediate actions in the continuity of the environment, and thus reproduces and reinforces existing social structures. In most cases, Archer notes that for communicative reflexivity, context is more important than projects.

The second mode of internal conversations is autonomous reflexivity. It corresponds to those kinds of lonely internal conversations carried out with a performative aim. This time, the actor displays an individual project linked to a part or the whole of a broader structure, and he endeavors to stick to this personal project. In some cases, this internal conversation can be accommodative and can adjust or modify itself if the objectives of collective action evolve. Archer remarks that this kind of reflexivity tends to mediate actions that result in structural discontinuities. Contrary to communicative internal conversations that aim at maintaining cohesion within the group and social structures, the autonomous actor's sense of opportunism is more likely to result in regular transformations of social structures.

The third and last mode of internal conversations corresponds to what Archer labeled metareflexivity. It consists in lonely internal conversations... about internal conversations. The mental life of the individual is dominated by thoughts concerning his or her own thoughts and actions. 'Haunted' by questions about sense, meta-reflexives are guided by a certain ideal or lifelong project to which they are willing to sacrifice anything ("Preoccupied with their selves (or perhaps I should say with their 'souls'), they seek self-knowledge and practice selfcritique for the sake of self-improvement and self-realization", Vandenberghe, 2005, p 235). Contrary to the two other kinds of internal conversations, meta-reflexivity implies a degree of rigidity with regards to the project and a rejection of any form of compromise. Basically, more so than communicatives or autonomous people, meta-reflexives are frequently willing to pay a high price (symbolic or material) to preserve their projects. Thus, "instead of responding to them strategically, this group will generally be willing to pay the structural price for relocating themselves in a different context, which they evaluate as preferable. Hence, their biographies will not only be restless trajectories, they will also be checkered patterns of upward, lateral, and most significantly, downward mobility" (Archer, 2003; p 274).

Beyond these three internal conversations, Archer also suggests two misalignments in the reflexive processes. Each one corresponds to particular forms of internal conversations: fractured reflexivity and near non-reflexivity.

Fractured reflexivity defines a reflexive process that only works to a certain point, after which internal conversations and concerns can no longer be correlated. In some cases, reflexivity is displaced. A change in the conditioning context makes the usual internal conversation ineffective. The agent is like a French-speaking person living in a German-speaking country. His/her way of treating information is not adapted to the sociocultural matrix on which other actors are drawing. In other cases, reflexivity is impeded. In this case, the actor does not manage to adapt a mode of reflexivity to his or her context. It may thus be a situation where an individual develops autonomous, communicative or meta-reflexivity, but only on an 
embryonic level. The agent is like a person living in a foreign country and mastering only the very basic principles of the language. Both impeded and displaced reflexivities imply a lack of control on the part of the agent over his/her life.

The near non-reflexivity is linked to a particular case of internal conversation, where an actor seems to experience difficulties in feeling like the subject of his/her own actions and thus readily yields to a form of fatalism. He/she perceives him/herself as an object with almost immutable properties, which the social environment will either select or not. Instincts are the real drivers of actions and intentionality has almost disappeared: "he thus lives as Humean man, a slave to his passions, without using internal reasoning as their 'ingenious servant', to compare and contrast the merits of concrete projects for the realization of his desire" (Archer, 2003; p 338).

Within the internal conversation framework, Archer also takes into account the (long and difficult) possibility of changes in the dominant modes of reflexivity of a given actor. But her empirical device does not enable her to validate these trajectories. However, with the wisdom of retrospection, she notes some obvious changes, such as reflexivity moving from an autonomous state to a fractured state.

Besides the aforementioned problem with description of trajectories, Archer also avoids several other difficulties. Can an individual display hybrid reflexivity modes? This point is not really addressed. Rather, each interviewee is placed in clear typological situations (and who seems to endorse the thesis of an incompatibility of reflexivity modes, at least in their effects). Nor does she analyze the problem of artifact-mediated interactions (such as in an IS environment). Indeed, does the recurrent use of artifacts in everyday practice change the nature or modus operandi of internal conversation? Archer may also be criticized for her logico-deductive and illustrative stance. She seems to be aware of her fallacy when she states, rather strangely ( $p$ 164): "Obviously, all the above is open to a charge of verificationist induction, which only broader investigation could dispel. Nevertheless, there is one defense against the charge that the analysis was simply nudging people into a typology. That is that only fifteen of the twenty subjects could be clustered into one of the three modes of reflexivity. The remaining five interviewees simply do not fit." Regarding the core concept of internal conversation, Vandenberghe (2005) emphasized the effects of Archer's alinguistic vision of reflexivity. By missing the 'linguistic turn', Archer underplays the role of narration in reflexivity. According to Vandenberghe (2005, p 233) " Narration is what 'emplots' and directs the internal conversation. To properly understand how personal identity is formed, one has to understand that the internal conversation takes the form of a narration, while the narration itself has to be understood as a conversation that is intrasubjectively intersubjective." 


\section{ACCOMMODATING INTERNAL CONVERSATION THEORY TO SOCIOTECHNICAL REFLEXIVITY}

In order to make sense of sociotechnical reflexivity and to provide some answers to the aforementioned difficulties, we conducted a series of semi-structured interviews with a diverse group of French managers. We firstly describe the research design and then apply Archer's theoretical framework to IS contexts linked to network tools (intranets and groupware systems).

\subsection{Research Design}

Grasping an individual reflexivity mode is obviously a very difficult exercise. In fine, two broad research strategies can be implemented to study a user's internal conversations: an 'introspective' strategy or a 'situational' strategy.

The former is based on a narrative carried out by the actor him/herself, who will auto-analyze his/her own reflexivity processes, generally away from the situation under study. This can be accomplished by means of semi-structured interviews like those carried out by Archer (2003) who asked the individual to explain his/her reasoning on key themes (planning, budgeting, imaginary conversations, etc). The individual will thus exert his/her meta-reflexive capacity, and investigate his/her own reflexivity modes.

The latter is based more on a patient following of the actor's discourse while immersed in his/her sociotechnical environment (thus ultimately producing "a life story-telling", see Bertaux (2005)). In social sciences, "the life story-telling is based on a particular sort of interview, the narrative interview, during which the researcher asks somebody (...) to tell him all or a part of his experience" (Bertaux, 2005; p 11). It is a specific interpretative method (see Walsham, 1993, 1995). The objective is to spot clear thought, to infer reflexivity modes starting from the actors' general discourse, or to ask him/her (by means of video/audio recording of his/her behavior at work) to clarify the reasoning he/she followed during the course of the action. This is notably what Von Cranach and Harré (1982) or Theureau (1992) suggest by what they call "auto-confrontation", which amounts to asking an actor for ex post commentary about his/her motivations and thought in front of a recording of his/her behavior (for an illustration, see Cahours and Pentimalli, 2004). The actor is thus assumed to directly exhibit his/her reflexivity process.

Our research adhered more to the second strategy by drawing on doctoral and post-doctoral field data on the study of organizational structuring, which seemed relevant to our purpose. Indeed, case-study methodology (see Yin, 2002) made it easier to link practice and discourse to elements of the context. Several materials we had at our disposal (namely the audio recording of the actor him/herself at the end of the interview, see the Appendix) turned out to be very relevant in grasping "imaginary conversations", and then articulating them with uses and attitudes. 
From an epistemological point of view, it seems that the situational method is less biased than the introspective one. Firstly, it makes it possible to minimize the actor's strategy of selfaggrandizement and valorization, ex post rationalizations and the temptation to present idealized reflexivity processes (different from the reflexivity in use). The in vivo feature of the method makes it possible to simulate or produce a conversation that is likely to be relatively authentic, because the auto-analysis directly applied to a past or current situation makes it possible to avoid some memory loss. Then, it can be reasonably assumed that this research strategy will also enable the researcher to treat data at a meta-level by studying the structure and logic of the actor's discourse.

The database which the research has drawn on is composed of 120 semi-structured interviews and auto-presentation of tools carried out between 1997 and 2004. The organizations are shown in table 1.

\begin{tabular}{|c|c|c|c|}
\hline ORGANIZATION & $\begin{array}{l}\text { PERIOD OF } \\
\text { STUDY }\end{array}$ & $\begin{array}{c}\text { TYPE OF } \\
\text { TECHNOLOGIES } \\
\text { EXAMINED }\end{array}$ & $\begin{array}{l}\text { NUMBER OF } \\
\text { INTERVIEWS }\end{array}$ \\
\hline $\begin{array}{l}\text { A military research } \\
\text { center in toxicology }\end{array}$ & 1997 & $\begin{array}{l}\text { A web browser (Internet } \\
\text { Explorer) }\end{array}$ & $\begin{array}{l}2 \text { researchers (the head } \\
\text { of the toxicology } \\
\text { department and one of } \\
\text { his researchers) }\end{array}$ \\
\hline $\begin{array}{lll}\text { A French } & \text { regional } \\
\text { newspaper } & \end{array}$ & 1997 & $\begin{array}{lrl}\text { A } r e b & \text { browser } \\
\text { (Netscape) }\end{array}$ & 2 journalists \\
\hline $\begin{array}{l}\text { A pharmaceutical } \\
\text { company }\end{array}$ & 1997 & $\begin{array}{l}\text { An Intranet and an e- } \\
\text { mail system (MS mail) }\end{array}$ & $\begin{array}{l}6 \text { people, mainly upper } \\
\text { managers of the } \\
\text { company (2 ClOs, a } \\
\text { management controller, } \\
\text { head of the animal and } \\
\text { vegetable health } \\
\text { department, R\&D head) }\end{array}$ \\
\hline $\begin{array}{l}\text { A consulting company } \\
\text { in IS and organization }\end{array}$ & 1997 & Intranet & $\begin{array}{l}2 \text { people (sales director } \\
\text { and resource manager) }\end{array}$ \\
\hline $\begin{array}{l}\text { A big industrial } \\
\text { company involved in } \\
\text { environmental activities } \\
\text { (water treatment, waste } \\
\text { and energy) }\end{array}$ & $\begin{array}{l}1999-2001 \\
2002\end{array}$ & Intranet and Groupware & 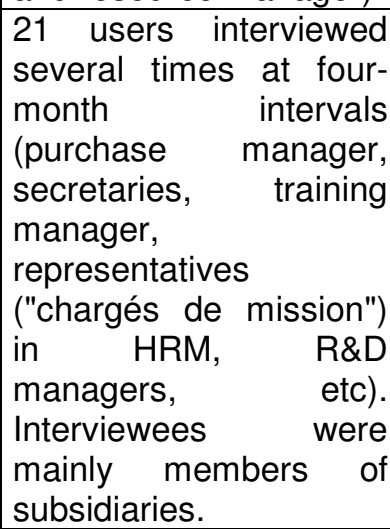 \\
\hline $\begin{array}{l}\text { A telecommunications } \\
\text { company }\end{array}$ & $1999-2000$ & Intranet & $\begin{array}{l}17 \text { people interviewed } \\
\text { several times at four- } \\
\text { month intervals } \\
\text { (technicians, salesmen, } \\
\text { planners, } \\
\text { managers, } \\
\text { administrators). }\end{array}$ \\
\hline A quality control firm & 2000 & $\begin{array}{lrr}\text { Intranet } & \text { and } & \text { a } \\
\text { Groupware } & \text { system }\end{array}$ & $\begin{array}{l}5 \text { interviews (2 regional } \\
\text { directors, one national }\end{array}$ \\
\hline
\end{tabular}




\begin{tabular}{|l|l|l|l|}
\hline & & (Lotus Domino) & $\begin{array}{l}\text { IS manager, one } \\
\text { engineer, } \\
\text { secretary). }\end{array}$ \\
\hline $\begin{array}{l}\text { A research center of a } \\
\text { large organization } \\
\text { involved in chemistry } \\
\text { activities }\end{array}$ & 2000 & Intranet (RP Intranet) & $\begin{array}{l}\text { interviews (CIO, } \\
\text { training manager, } \\
\text { documentation security } \\
\text { manager, security } \\
\text { manager, } \\
\text { engineer). }\end{array}$ \\
\hline $\begin{array}{l}\text { A university of anagement } \begin{array}{l}\text { Mnd } \\
\text { Economics }\end{array} \\
\text { interviews with IS } \\
\text { managers and 120 } \\
\text { questionnaires with IT } \\
\text { users; two years' direct } \\
\text { observation of the e- } \\
\text { learning system life } \\
\text { (one as the technology } \\
\text { manager) }\end{array}$ \\
\hline
\end{tabular}

- Table 1: Organizational background of the interviews

A high level of heterogeneity was aimed for in choosing organizational (linked to various sectors and structures) and individual (managers and lower-level staff) profiles. The technologies under study were all network technologies, more specifically online technologies (Groupware tools, Intranets, Web, e-mail systems, etc).

The meeting was divided into two parts (see the Appendix). First, questions were asked about instrumental use of IT, and the user talked about his/her everyday use. Then, the interviewee was asked to demonstrate the primary software he/she was accustomed to using and to comment out load on the process. The primary goal was to invite managers to evoke their experience of technology within the organization. Without looking for sociotechnical reflexivity modes (our initial target was the study of sociotechnical structurations), managers were thus induced to reproduce internal conversations or to evoke "imaginary" conversations. The entire meeting (which on average lasted about one hour) was recorded and coded.

The coding was based on a Strauss and Corbin (1998) grounded procedure and used in a "Straussian" way (Locke, 1996). This version "allows for the potential of prior theory, literature and personal and professional experiences to guide researchers' data analysis" (Boudreau and Robey, 2005, p 6). Thus, the coding process was strongly influenced by Archer's categories. First, we delimited in the transcripts all speeches that corresponded to thoughts about the technical or social contexts of the actors ("open coding"). Thus, descriptive categories, sub-categories and properties related to the internal conversation theory were clearly stipulated. Then, these reflexive processes were linked to main modes of reflexivity, reflexive misalignments and social changes, which then underwent a more interpretive coding (axial coding). Lastly, reflexivity processes and social evolutions were combined (selective coding). This consisted mainly in adding a final code to each transcript or broad parts of the interviews. The overall process resulted in a final thematic dictionary. Our research aimed to assimilate-accommodate the overall conceptual scheme in Piaget's sense $(1947,1977)$. In other words, through our fieldwork, we tried to identify the reflexivity modes expressed by interviewees (by establishing connections with Archer's typology, i.e. assimilation), and to reframe the typology or the framework in case of anomalies (i.e. accommodation). 
In short, numerous users' comments either in front of the technology or during interviews corresponded to the typology mentioned in section 2.2. Some users and extracts of interviews epitomized specific types of internal conversations. Thus, one of Archer's fundamental conclusions was confirmed: internal conversations (here related to technology-mediated interactions) do not have a universal form ${ }^{5}$. Nevertheless, a new kind of internal conversation was also uncovered, and the fieldwork has resulted in the evolution of the conceptual framework (at least for an IS environment).

\subsection{Archer's Framework Applied to an IS Environment: the Assimilation Process}

Several users and extracts of interviews epitomized Archer's reflexivity modes. They clearly illustrated the way autonomous, communicative or meta reflexivities combine context, concerns and projects. Other users or extracts of interviews were more problematic, as they did not correspond to Archer's configurations. The next section will discuss this latter group, and the subsequent evolutions and accommodations of the overall framework.

In the case of communicative reflexivity, the commentary of an internal auditor of a big French telecommunications company was similar to that stipulated by Archer for this type of situation. From his point of view, technology was a way to keep in touch with close colleagues (who were members of the same theater company financed by the firm). This group took precedence over the formal organization and official goals of ICT. Interestingly, when problems arose, this manager preferred appealing to certain colleagues rather than relying on the official hot line. Internal solidarity took precedence over official support ("In the case of a problem, I do not call the people that manage the system. I call close friends. (...). For instance a colleague I used to work with in Lyon. We have a common history. We do not work together anymore but we are still colleagues."). Incentives for consultation depended more on exogenous factors ('events') than on endogenous ones. Furthermore, it was noticed that during the second interview, this internal auditor displayed more "fractured" conversations. Indeed, he was one of those belonging to the headquarters that was to be 'redeployed' in operational units. His work background was somewhat transitional, which impeded his reflexivity about Intranet evolution ("I have no Intranet use related to my position. This can be linked to the fact that my current job is, as we speak, being restructured. If I have the option of maintaining my job here, it is undeniable that the Intranet would grow in importance... Basically, this may be due to my current situation... Thus, I do not have enough experience or objectivity to appraise all the potentialities [of the technology]."). Interestingly, this communicative actor also enacted some specific reflexivity modes, depending on the technology at hand. If e-mail was clearly used as a communicative tool (a means to exchange with "colleagues"), intranet documentary databases or more specific geomarketing software mentioned during the interview were discussed in more autonomous ways ("those are work tools").

\footnotetext{
${ }^{5}$ Counterintuitively, "most interviewees volunteered that they themselves assumed the practice of interior dialogue to be universal, and, even more importantly, that they presume we all did it in much the same way." (Archer, 2003; p 161).
} 
As regards autonomous reflexivity, a salesman also belonging to the telecommunications company illustrated this category. Internal conversations emerging from the interview were more 'performative' than those of the internal auditor. Technology was systematically brought closer to the task at hand and contributed more directly to performance. The agent was quite opportunistic in his use of the tool and in the way he managed his work. He essentially desired to dominate the technology. A financial controller who also epitomized this kind of internal conversation suggested that: "These are only tools. This means that they follow the goals we give them. These are stupid things." More than any other modes of reflexivity, it was noticed that internal conversational sequences related to this category were constituted by factual descriptions of interactions.

The case of meta-reflexivity was strongly embodied by a journalist who had experienced numerous job mobilities. The interviewee's suspicion of the meaning of the new technology was palpable, both during the interview and during the presentation of technology by the interviewee himself. Thus, beyond any thought linked to organization, he was inclined to discuss both sociological and biographical issues. Moreover, the interviewee continuously addressed his own journalistic work, comparing it to a vocation (such as the priesthood) rather than merely a job to perform. It was precisely in view of this concern that the technology was assessed. As he was involved in the journal's website management, the interviewee returned at several points during the interview to his desire for a "new writing" in the use of Internet technologies by the media ("People are wrong. They see the Internet as a new way to diffuse information, and not as a new media. But, we should consider a new kind of writing, which is not at all what is being done at the moment"). In his view, this revolution was still something that had yet to be carried out by most journalistic web sites.

Impeded reflexivity was particularly present in some of the internal conversations of another young salesman of the telecommunications company already mentioned. After he switched from the department (and applications) he was used to working in and on, he experienced difficulties in continuing work in the way to which he was accustomed. The new interfaces were far too different ("Everything appeared more sophisticated"). The culture of the team was quite different as well. He had to make a considerable effort to forget his old work habits.

Displaced reflexivity dominated the internal conversations of a financial controller working in a French company involved in environmental activities. His job consisted mainly of reporting various figures related to subsidiaries to the headquarter managers, which required him to be frequently in touch with his network of correspondents. However, the more he used his e-mail system, the more demanding his correspondents became about the frequency of his correspondence. Finally, all this became very disruptive to his task. When he was concentrating on a report or analysis, the email system regularly disturbed him with a 'beep' signaling the receipt of new messages. Thus, the controller decided to change the way he managed the mail system. He stated that, "today, I manage my mail quite differently. I open it in the morning. I read my messages. I print them. I close the system. Then I open it again at 2 pm and see what's new. I close it, and open it once more at the end of the day." Initially, the network of correspondents tried to encourage the controller to return to a more continuous management of his emails, which resulted in a form of displaced reflexivity ("First reactions were: 'Alexandre, did you receive the mail I sent you? You did not answer it. Is there something wrong between us?' No... I had simply not read it yet. Thus, people, as soon as they send you a message, they expect you to give a quick answer. This expectation of an 
immediate answer has been engendered by [the instantaneous nature of] electronic communication"). However, the controller did not succumb to pressure and continued to use the technology in his periodic manner. Here we notice a move from 'communicative reflexivity' (strongly linked to the network of correspondents met during internal business trips) to 'impeded reflexivity' and more recently, 'autonomous reflexivity'. The controller insists on the extra performance brought by technology. He concluded, "I realized that by opening my mail in the morning and in the afternoon, I could be kept abreast of most significant requests and treat them in a more effective way than when I left my mail opened all day long." Finally, his new reflexivity was both autonomous and communicative. On the one hand, his alternative use of technology was a way to improve his individual effectiveness. On the other hand, e-mail was still used as a way to be in touch with a specific network involved in complex reporting activities, requiring continuous co-approvals. The controller thus corresponded to a mix of reflexivity modes (an 'autonomous communicative'?).

Near non-reflexivity was clearly the case with an assistant manager in the telecommunications group. She adopted a relatively passive attitude vis-à-vis technology. Her internal conversations were experienced passively rather than actively ("There's always further to go. Sometimes, we do not know where to stop. With regards to all that's related to the use of the Internet, it seems endless"). Her speech was often hesitant, and her understanding of the issues and tasks at hand was unclear. She experienced considerable difficulties in appropriating the tool. In the same way, a purchase manager stated that "It [the Internet / the new technology] is magic. For us, it's magic". Furthermore, this individual often used very general and collective grammatical formulations, talking about 'one' or 'we' ("The most important things today are cohesion and technology. If one does not stick to it, he will quickly be out of the loop... He can still send snail mail, if he wants. He will tell you that he does not understand what you mean, if you really talked about this and that. But these kinds of things are over. There are many people that will tell you the same thing I'm telling you"). Technology and its impact were supposed to be mechanistic elements. As in the case of communicative reflexivity, the drivers of Internet use were linked more to "the pressure of events" than to endogenous ones, such as internal autonomous deliberation.

\subsection{Archer's Framework Applied to an IS Environment: an Adaptation of her View on Reflexivity}

But if many commentaries epitomized Archer's framework and typology, others resulted in a clear adaptation of it. First, in view of some semi-structured interviews, a fourth kind of tendency emerges in the reflexive process: hyper-reflexivity. Some interviewees showed an intense reflexive capacity as regards their actions. This was akin to a sort of "intellectualization" of their interactions, especially those with technology. A technical infrastructure manager epitomized this particular case. During the interview, his self-analyses were trapped in the endless examination of alternatives and their hypothetical consequences ("So, if I tell you this... you will tell me..."), which ultimately resulted in an absence of answers to many questions. The feedback and second-guessing to which he constantly subjected himself paralyzed his actions. 
More surprisingly perhaps, the fieldwork also lead to more fundamental adaptations of the model. Most users did not fit easily into a single category (see the case of the financial controller). Indeed, depending on the kind of technology they were discussing (e-mail systems, groupware, specific intranet tools, etc.), many interviewees evinced several kinds of internal conversations (see the internal auditor). The same person could thus be communicative in his/her interaction with email, autonomous with the groupware technology, and meta-reflexive with the Web. Nonetheless, and in agreement with Yates and Orlikowski's 1992 genre theory, no mechanist relationship between a technology and a mode of reflexivity was identified. Some actors were very communicative with their e-mail (most of them at the telecommunications company), whereas others were more autonomous. In addition -- and this could result in another adaptation of Archer's overall framework -- these mental schemes were not systematically and harmoniously integrated into a clear, general mode of reflexivity; a person could be multimodal without any particular reflexivity mode dominating his/her reflexivity process (that is, at least according to the image he/she presented during the interview or the technology presentation). More surprisingly, reflexivity processes seemed absent in many presentations where instincts and habits dominated the mental activity. This was clearly illustrated in the final part of our research protocol, where interviewees were asked to demonstrate the use of an application aloud. The beginning of the presentation (the opening and initial use of the application) was often silent. As the presentation progressed, researcher questions and participant discovery of unfamiliar situations (for instance, when the screen did not display the information expected) provoked a higher level of reflexivity. But internal conversation was apparently incompatible with routines. Instead, it is likely that internal conversation were facilitated by instincts and routines ("By freeing the conscious mind from many details, instincts and habits have an essential role. If we had to deliberate upon everything, our reasoning would be paralysed by the weight of data," says Hodgson, 2004). Finally, the fieldwork abounds with evidence of verbalization and reflexivity (and the "I") as background infrastructure, organizing but largely silent, such as in ICT-mediated interactions. Internal conversations are both facilitated and constrained by routines formed through previous interactions (and crystallized in the "me").

Given the above, four exploratory propositions may be helpful as regards the adaptation of internal conversation theory to IS. First, it seems that the same actor can demonstrate various sociotechnical reflexivity modes, depending on the kind of technology he/she is using $(\mathrm{P} 1)$. Second, actor's internal conversations are not necessarily integrated in a clearly defined general reflexivity mode, and thus lack overall coherence (P2). However, some archetypal individuals embody a single reflexivity mode in their relationship with technology (P3). Lastly, reflexive processes may be more or less active (in accordance with Giddens, 1984) (P4). Sometimes, routines and instincts dominate an actor's agency. As Heidegger said (1927), the world is "ready-to-hand". The "me" as conditioned by past interactions monitors agency. Conversely, an actor can also become more conscious of actions mediated by artifacts (such as those involving ICT) or current interactions with other actors. The world is then "presentat-hand" (Heidegger, 1927). The "I" and "You" are the main drivers of agency, which is more or less disconnected from the "Me" modality. 


\section{CONCLUSION: CONTRIBUTIONS, LIMITATIONS AND AREAS FOR FUTURE RESEARCH}

First, we will discuss the contributions internal conversation makes to Information Systems, and then we will explore its limitations and alternative means of analysis.

\subsection{Theoretical and Methodological Contributions}

This research is a first step (along with others such as Morton, 2006, Dobson, Myles and Jackson, 2007 and Mutch, 2007) to place the critical realist framework in the concrete context of management and IS. As underscored in the introduction, empirical attempts are still very rare in critical realist literature, even among those interested in social critical realism. Yet this research demonstrates that empirical realism is in fact highly applicable to critical realism, all the more so because it explores and modifies the original framework. Two modifications are particularly worth noting: the addition of an extra category (hyper-reflexivity) and four exploratory propositions with regards to the integration and combination of modes at the individual level. Of course, one may wonder if these adaptations only apply to sociotechnical reflexivity and internal conversations in an IS environment, and we believe that further research is necessary to substantiate our argument in atechnical environments and unmediated reflexivity process.

Moreover, this research responds to Thompson's 2004 request for a deeper and more explicit presence of reflexivity and the biographical realm in IS social modeling. Indeed, we think that Archer's perspective is a markedly new way to make sense of sociotechnical reflexivity and sociotechnical change. Users are considered reflexive agents involved in various types of internal conversations with, or about, ICT. It is thus a very good answer to the problem raised in the introduction: i.e., the weak modeling of reflexivity modes in most IS research. Archer also suggests a relevant description of the biographical realm, and a perceptive distinction between 'person', 'agent', 'actor'. Thus, instead of returning to Giddens' core ideas (as Thompson did, see Figure 3), the issue of weak modeling has been addressed by means of a critical realist approach. 


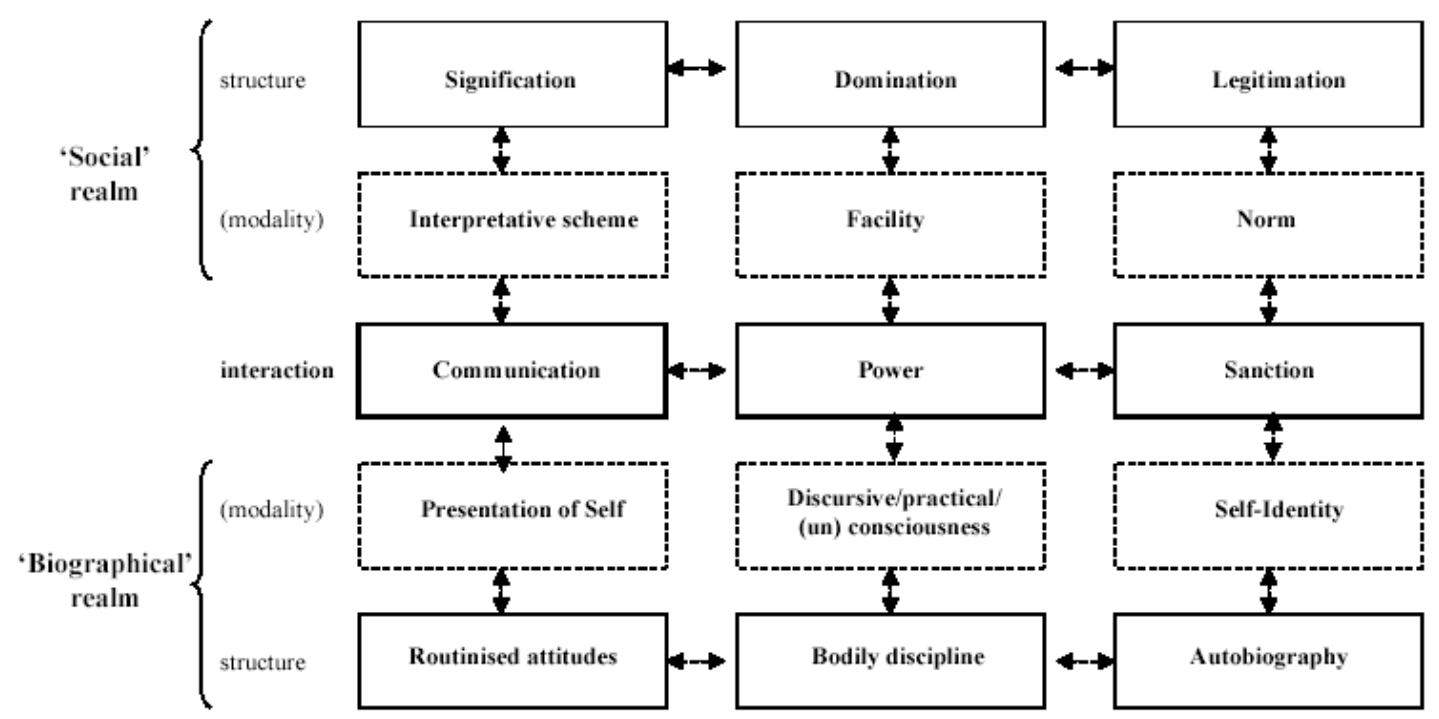

- Figure 3: The social and biographical realms reconciled, as per Thompson (2004, pp. 14-15)

In keeping with the above, "routinized attitudes", "bodily discipline" and "autobiography" may all be considered components of internal conversations or facets of internal conversations. These would be 'actualized' in the "presentation of self", "discursive/practical (un)consciousness" and "self-identity", through "communications", "power" exercise and "sanctions". Here, structuration and critical realism could result in interesting crossfertilizations, while maintaining their independent epistemological stances (see for instance the temporal vision of reflexivity defended by Archer in Bagguley, 2003).

For IS practice, implications of an understanding of sociotechnical reflexivity are extremely significant in (re-)design, communication and training activities. Should an IS practitioner be involved in the training of a "communicative manager", he/she will have to take into account the narrow network of communicating agents that the manager is accustomed to working with $^{6}$. In contrast, an autonomous reflexive will probably require more individual and performative modalities. Likewise, the interface design or the way communication or animations are achieved will clarify actors' reflexivity process. In the case of a group of metareflexive users (such as the archetypal journalist described earlier), private spheres and philosophies of life cannot be ignored. Planning of training, communications or interface would benefit from the integration of reflexivity modes.

As a further contribution, this research implies specific conceptualizations of reflexivity and technology, at least compared to structuration theory (which is often compared to social critical realism, see Archer, 1995). Indeed, critical realism emphasizes intransitive properties of artifacts, relative to which actors are exterior. In line with Porpora's 1998 discussion on

\footnotetext{
${ }^{6}$ We experienced this as project manager of an e-learning facility. In the early stage of the project, three secretaries involved in the same department were trained separately, which resulted in poor results. Then, realizing that we were facing communicative reflexives, it was decided to train them during a single session, which resulted in a much better appropriation of the tool.
} 
structures, structurational and critical realist conceptions of reflexivity and technology could also be contrasted:

\begin{tabular}{|c|c|c|}
\hline & $\begin{array}{l}\text { STRUCTURATIONAL } \\
\text { APPROACHES OF ICT }\end{array}$ & $\begin{array}{l}\text { CRITICAL REALIST } \\
\text { APPROACHES OF ICT }\end{array}$ \\
\hline $\begin{array}{l}\text { Related sociotechnical } \\
\text { reflexivity process }\end{array}$ & $\begin{array}{l}\text { A continuous feedback for action } \\
\text { and structures. } \\
\text { Technology is part of the reflexive } \\
\text { process }\end{array}$ & $\begin{array}{l}\text { A continuous feedback in and for } \\
\text { action. } \\
\text { Reflexivity is an autonomous and } \\
\text { specific instance, the "I". }\end{array}$ \\
\hline ICT status & $\begin{array}{l}\text { A 'socio-cognitive scheme', a set of } \\
\text { habits (resulting from interactions } \\
\text { with a world whose reality and } \\
\text { exteriority is not denied) } \\
\text { This scheme will constrain or } \\
\text { encourage forthcoming interactions. } \\
\text { ICT practice reproduces or } \\
\text { transforms sociomaterial structures } \\
\text { (which are only a trace in actors' } \\
\text { mind, see Jones, 1999) }\end{array}$ & $\begin{array}{l}\text { An 'object in practice', both a } \\
\text { physical and social artifact, part of } \\
\text { the "Me". A constraining, inciting } \\
\text { and enabling network of physical } \\
\text { and social components. } \\
\text { Social and physical structures are } \\
\text { reproduced or transformed through } \\
\text { interactions. }\end{array}$ \\
\hline $\begin{array}{l}\text { Related ICT appropriation } \\
\text { process }\end{array}$ & $\begin{array}{l}\text { An assimilation-accommodation } \\
\text { process (as described by Piaget, } \\
\text { 1947, 1977 and Bouchikhi, 1991). } \\
\text { ICT use and ICT structure are two } \\
\text { sides of the same coin. }\end{array}$ & $\begin{array}{l}\text { An interactional process partially } \\
\text { intransitively inscribed. ICT use and } \\
\text { ICT structures define each other } \\
\text { alternately. Technology structures } \\
\text { an opportunity scope partially } \\
\text { independent of actors' perceptions. }\end{array}$ \\
\hline
\end{tabular}

- Table 2: Structurational and critical realist conceptualizations of ICT artefacts and related sociotechnical processes

Basically, ICT is perceived to be more of a virtual nature from a structurational than in a critical realist perspective. This stance has been criticized by some critical realists, who defend a different conceptualization of technology. For instance, Dobson argues that a central issue "with Orlikowski's model is the equating of technology with structure, thus providing a virtual existence, and the technology is "made real" only in instantiation"7 (2001, p 208). ICT is thus a 'trace' in the memory of actors. Interestingly, technology becomes part of the reflexivity process from a structurational perspective, whereas it is more exogenous and autonomous from a critical realist stance.

\footnotetext{
${ }^{7}$ But critical realists do not really explain why this should be a problem. Furthermore, in her recent writings Orlikowski (2006) gives more emphasis on materiality.
} 


\subsection{Limitations and Directions for Future Research}

Internal conversation theory and its empirical use as proposed here has several weaknesses. First, the internal conversation construct seems a bit ahistorical and disconnected from broader institutional trends. In contrast with Giddens (1991) who insists on "institutional reflexivity", the relation of Archer's vision of internal conversation to individual emergent properties is emphasized. This may be the result of a model whose analytic nature (such as in its distinction of three different cycles of morphogenesis) makes a systemic vision hard to discern. Our research, which is directly related to individual actors and their connections to the organizational context, does not solve the problem.

Another limitation relates to the theoretical sources used in this study. Archer's theory was the primary source, which is unfortunate as other frameworks may also have been useful to refine critical realist concepts. The overall theoretical framework may benefit from cautious crossfertilization with other sociological theories such as structuration theory. Giddens' recent theorization of reflexivity and self-construction, or earlier writings about "ontological security", may be a means to strengthen the combination of instinctual and intentional processes. The lack of historicity noted above, the dimensions of internal conversations and their temporal modalities, and the way both beliefs and positions are enacted in the reflexivity process could be illuminated through such collaboration. The use of Bourdieu's theory of practice may also be a helpful detour. His concept of "habitus" (Bourdieu, 1977, 1990) can be combined with that of reflexivity in order to grasp more deeply personal identity (Adams, 2006). This may also be a way to stick to the 'linguistic turn' (or rather, the 'sociolinguistic turn') stressed by Vandenberghe (2005).

Lastly, from a methodological point of view, the organizational settings and interviewees were rather specific (mainly firms and managers). Such was also the case for technologies under study (intranets and groupware systems for the bulk of our interviewees), with high levels of interpretive flexibility. Even if, as suggested in the first part, there is very little determinism in the reflexivity mode-technology relationship, more heterogeneous empirical materials would be helpful in strengthening our conclusions. As stressed by Swanson and Ramiller (1997), a given technology is immersed in an institutional context, or in other words, is embedded in an inter-organizational "organizing vision". If it is assumed that reflexivity is also inscribed in institutions and broader historical trends, both individual and technical heterogeneity are extremely important. Hence, a complementary field-study on ERP use, for example, in an administrative structure would be a relevant next step.

Future research could also address the relationship between temporal orientation and reflexivity. It seems that Archer's framework could be applied to more general discourses on temporal structuring in organizations. It was observed in section 2.1 that reflexivity processes entail a combination of past, present and future actions. Indeed, in conformity with Orlikowski and Yates' (2002) essay about time as both subjectively and objectively defined, it should be mentioned that all internal sociotechnical conversations discussed here may involve specific relationships with time. For a 'communicative' user, the group imposes various steps in the learning process, defining the rhythm and duration of interactions. Usage time is, ultimately, group time. For 'autonomous' users, it is more the performance and the speed of 
the technology's evaluation by the whole or a part of the organization that defines the independent user's rate of learning and appropriation. In this case, usage time is related to the organization's temporal orientation. Lastly, as regards meta-reflexives, it is the user's holistic approach to technology and life that defines the degree of interest and rate of interaction. For them, time in front of technology is more indefinite than for other kinds of users. It is also more individual. In each case, time devoted to internal conversation about technology (whether based on direct interactions or not) could correspond to specific types of constraints or capabilities. An interesting research agenda might involve confirming and deepening these initial insights.

More empirical work should also be done in comparing sociotechnical and atechnical reflexivity. The four propositions are of a very initial nature and are specified in broad terms. They should be confirmed or refuted by complementary empirical studies, and refined by other theoretical perspectives (such as structuration or Bourdieu's theory of practice). To do this, some specific case studies targeting various ICT users (such as ERP adopters) are necessary. As Archer herself (2003) suggests, the typology used is unlikely to be exhaustive. Even if our own work leads only to one new form of internal conversations ("hyperreflexivity"), it can be assumed that other categories or dimensions are yet to be discovered, along with new ways to combine them.

\section{Acknowledgements}

We wish to thank Claude Pellegrin, Vladislav Fomin, Lin Xueling, as well as the associate editor (Geoff Walsham) and two anonymous reviewers for their detailed feedback on the manuscript. We also acknowledge the great help of Kirsten Albertsen in the proofreading of this article. 


\section{REFERENCES}

Adams, M. (2006). Hybridizing Habitus and Reflexivity. Sociology, 40(3), 511-528.

Alter, N. (2000). L'Innovation Ordinaire, Paris: PUF.

Archer, MS. (1982). Morphogenesis Versus Structuration: on Combining Structure and Action. The British Journal of Sociology, 22(4), 455-483.

Archer, M. (1988). Culture and Agency: The Place of Culture in Social Theory. Cambridge: Cambridge University Press.

Archer, MS (1995). Realist Social Theory: the Morphogenetic Approach, Cambridge: Cambridge university press.

Archer, MS., Bhaskar, R., Collier, A., Lawson, T. \& A. Norrie. (1998). Critical Realism, Essential Readings. London: Routledge.

Archer, MS. (2000). Being Human: The Problem of Agency. Cambridge: Cambridge University Press.

Archer, M. (2003). Structure, Agency and The Internal Conversation, Cambridge: Cambridge University Press.

Bagguley, P. (2003). Reflexivity Contra Structuration. Canadian Journal of sociology, (28), 133-152.

Barrett, M. \& Walsham, G. (1999), Electronic Trading and Work Transformation in the London Insurance Market. Information Systems Research, 10(1), 1-22.

Barrett M., Sahay, S. \& Walsham, G. (2001). Information Technology and Social Transformation: GIS for Forestry Management in India. The Information Society, (17), 5-20.

Bertaux, D. (2005). Le Récit de Vie, Paris: Armand Colin.

Bhaskar, R. (1979). The Possibility of Naturalism. London: Harvester, last edition in 1998.

Bouchikhi, H. (1991), Structuration des Organisations. Paris: Editions Economica.

Boudreau, M. \& Robey, D. (2005). Enacting Integrated Information Technology: a Human Agency Perspective. Organization Science. 6(1), 3-18.

Bourdieu, P. (1977). Outline of a Theory of Practice. Cambridge: Cambridge University Press.

Bourdieu, P. (1990). The Logic of Practice. Cambridge: Polity Press.

Brannick, T \& Coghlan, D. (2006). Reflexivity in Management and Business Research: What Do We Mean? Irish Journal of Management.27(2), 143-161.

Cahour, B. \& Pentimalli, B. (2004). Conscience Périphérique et Travail Coopératif dans un Café Restaurant. Activités, 2(1), 50-75.

Callon, M \& Latour B (1990). La Science Telle qu'elle se Fait, Paris: Editions La Découverte.

Callon, M. \& Latour B. (1992). Aramis, ou l'Amour des Techniques. Paris: Editions La découverte.

Crozier, M. \& Friedberg, E. (1977). L'Acteur et le Système. Paris: Editions du Seuil.

Desanctis, G. \& Poole, MS. (1994). Capturing the Complexity in Advanced Technology Use: Adaptative Structuration Theory. Organization science. 5(2), 121-146.

DiMaggio, PJ. \& Powell, WW. (1991). Introduction. in Powell WW. and DiMaggio PJ. (Eds.), The New Institutionalism in Organizational Analysis, Chicago: University of Chicago Press, 1-38.

Dobson, P.J. (2001). The Philosophy of Critical Realism—an Opportunity for Information Systems Research. Information Systems Frontier. 3(2), 199-201.

Dobson, P., Myles, J. \& Jackson, P. (2007). Making the Case for Critical Realism: Examining the Implementation of Automated Performance Management Systems. Information Resources Management Journal. 20(2); 138-153.

Emirbayer, M. \& Mische, A. (1998). What is Agency? American Journal of Sociology. 103, 9621023. 
Fleetwood, S. (2005). Ontology in Organization and Management Studies: a Critical Realist Perspective. Organization. 3(12), 197-222.

Fuller, S. (1993). Philisophy, Rhetoric and the End of Knowledge: the Coming of Science and Technology Studies, Madison, WI: university of Wisconsin.

Goffman, E. (1967). Interaction Ritual. Boston: Doubleday.

Goffman, E. (1974). Frame Analysis. Boston: Harvard university press.

Giddens, A. (1979). Central Problems in Social Theory. SF: University of California press.

Giddens, A. (1984). The Constitution of Society: Outline of a Theory of Structuration. SF: University of California press.

Giddens, A. (1991). Modernity and Self-Identity: Self and Society in the Late Modern Age. Boston: Stanford University Press.

Heidegger, M. (1927). Being and Time. NY: HarperOne; revised edition (August 1, 1962).

Hodgson, G. (2004). The Evolution of Institutional Economics: Agency, Structure and Darwinism in American Institutionalism. London: Routledge.

Johnson, P. \& Duberley, J. (2003). Reflexivity in Management Research. Journal of management studies, (40), 1279-1303.

Jones, M. (1999). Structuration Theory. pp. 103-134, in Rethinking Management Information Systems, Currie, WL. \& Galliers, B., Oxford: Oxford university press.

Klein, H. (2004). Seeking the New and the Critical in Critical Realism: Déjà Vu?. Information and Organization, 14(2), 123-144.

Lamb, R. \& Kling R. (2003). Reconceptualizing Users as Social Actors in Information Systems Research. MIS Quarterly, 27(2), 197-235.

Latour, B. (1987). Science in Action. How to Follow Scientists and Engineers Through Society (1st ed.). Milton Keynes: Open University Press.

Latour, B. (1995). Social Theory and the Study of Computerized Work Sites. Paper presented at the IFIP WG8.2, Cambridge, UK.

Locke, K. (1996). Rewriting the Discovery of Grounded Theory after 25 years. Journal of Management Inquiry, 5(3), 239-246.

Mingers, J. (2004). Real-izing Information Systems: Critical Realism as an Underpinning Philosophy for Information Systems. Information and organization, 14(2), 87-104.

Monod, E. (2004). Einstein, Heinsenberg, Kant: Methodological Distinction and Condition of Possibilities. Information and Organization, 14(2), 105-121.

Morton, P. (2006). Using Critical Realism to Explain Strategic Information Systems Planning. Journal of Information Technology Theory and Application. 8(1), 1-21.

Mutch, A. (2002), Actors and Networks or Agents and Structures: Towards a Realistic View of Information Systems. Organization, 9(3), 477-496.

Mutch, A. (2003). Constraints on the Internal Conversation: Margaret Archer and the Structural Shaping of Thought. Journal for the Theory of Social Behaviour, 34(4), 429-450.

Mutch, A. (2007). Reflexivity and the Institutional Entrepreneur: A Historical Exploration. Organization Studies, 28, 1123-1140

Orlikowski, WJ. (1992). The Duality of Technology : Rethinking the Concept of Technology in Organizations. Organization Science, 3(3), 398-427.

Orlikowski, WJ. (2000). Using Technology as a Practice Lens for Studying Technology in Organizations. Organization Science, 11(4), 404-428.

Orlikowski, WJ \& Yates J. (2002). It's about Time: Temporal Structuring in Organizations. Organization Science, 13(6), 684-700.

Orlikowski, WJ. (2006). Material Knowing: the Scaffolding of Human Knowledgeability. European Journal of Information Systems, 15(5), 460-480. 
Piaget, J. (1947). La Psychologie de l'Intelligence. Paris: Armand Colin.

Piaget, J. (1977). La Naissance de l'Intelligence chez l'Enfant, Neuchâtel: Delachaux et Niestlé.

Porpora, D. V. (1998). Four Concepts of Social Structure. in Archer, M., Bhaskar, R., Collier, A., Lawson, T. and Norrie, A. (Eds), Critical Realism: Essential Readings, 339-355, London: Routledge.

Smith, M. (2006). Overcoming Theory-Practice Inconsistencies: Critical Realism and Information Systems Research. Information and organization, 16(3), 191-211.

Stones R. (2001). Refusing the Realism-Structuration Divide. European Journal of Social Theory, 4(2), 177-197.

Strauss, AL. \& Corbin, J. (1998). Basics of Qualitative Research: Grounded Theory Procedures and Techniques. Sage.

Swanson, EB. \& Ramiller NC. (1997). The Organizing Vision in Information Systems Innovation. Organization Science, 8(5), 458-474.

Theureau, J. (1992). Le Cours d'Action : Analyse Sémiologique. Essai d'une Anthropologie Cognitive Située, Berne: Peter Lang.

Thompson, MPA. (2004). Confessions of an IS Consultant or the Limitations of Structuration Theory. Cambridge research papers in management studies, $\mathrm{n}^{\circ} 1$.

Vandenberghe, F. (2005). The Archers, A Tale of Folk (Final Episode?). European Journal of Social Theory, 8(2), 227-237.

Von Cranach, M. \& Harré, R. (eds) (1982). The Analysis of Action. Recent theoretical and empirical advances, Cambridge Univ. Press- Editions de la Maison des Sciences de l'Homme, Cambridge-Paris.

Walsham, G. (1993). Interpreting Information Systems in Organisations. NY: Wiley.

Walsham, G. (1995). Interpretive Case Studies in IS Research: Nature and Method, European Journal of Information Systems. 4(1), 74-81.

Walsham, G. (2001). Making a World of Difference: IT in a Global Context. Chichester: Wiley.

Yates, J. \& Orlikowski, WJ. (1992). Genre of Organizational Communication: a Structurational Approach to Studying Communication and Media, The Academy of Management Review, 17(2), 299-326.

Yin, RK. (2002). Case Study Research. Design and Methods. Third Edition. Applied social research method series Volume 5. Sage Publications. California. 


\section{Appendix : Interview Guide}

Below is an example of the interview questions used with one company (involved in environmental activities, and referred to as "A" in the transcript). The same guiding questions were used for other companies, with minor changes made per the technology under examination.

\section{Background information}

Q1: Please tell me about yourself: your professional background and your role at A.

Q2: With which departments of A are you frequently in touch for your job?

\section{Instrumental uses of technology}

Q3: On the whole, what is the content of the messages you send with the e-mail system?

Q4: When are you used to accessing your e-mail system to check your messages?

Q5: What are the advantages and drawbacks of the e-mail system for your work?

Q6: How did you train yourself to use the tool? Did you experience any difficulties?

Q7: How has the profile of the people with whom you exchange e-mails evolved since your first use of the system?

Q8: What kind of information do you search for on the groupware system?

Q9: Do you have certain habits when you connect to the groupware system?

Q11: If you've already taken part in 'teamrooms' or forums, what were you looking for? Did you notice certain trends or themes?

Q12: How did Lotus change the way you do your job?

Q13: Did you notice any evolution in the way you use the Groupware system over the last few months?

Q14: What would you want the IS department to change in the Groupware tool?

Q15: What do you know about the future portal?

Q16: Is there anything else that came to mind as we talked today that you would like to add? 


\section{Comments in front of the technology}

Q17: Now I would like you to show me the Groupware system, while making comments out load. If it does not disturb you, I will keep recording what you say.

Note: These questions were used to manage semi-structured interviews. Thus, although the same set of topics was covered in each interview, the guide was not followed in a strict, rigid manner. That is why the specific wording of questions, the sequence in which topics were introduced, the follow-up questions that were asked, etc., varied from interview to interview. 